\title{
Inferior vena cava thrombosis as a possible cause of nephrotic-range proteinuria: two case reports
}

Yana Apostolova ${ }^{1 *}$, Patricia Mehier ${ }^{2}$, Salah D. Qanadli ${ }^{3}$ and Menno Pruijm ${ }^{4}$

\begin{abstract}
Background: Nephrotic-range proteinuria is a common reason for nephrological consultation in clinical practice. The differential diagnosis is wide, and generally focuses on different forms of glomerulonephritis, but other causes should not be overlooked, as illustrated in this article.

Case presentations: We report two female patients with nephrotic-range proteinuria. In the first case, a 46 year old Caucasian patient who suffered from extreme obesity (Body mass index (BMI) $77 \mathrm{~kg} / \mathrm{m}^{2}$ ), acute kidney injury and nephrotic-range proteinuria were discovered during an emergency consultation for acute abdominal pain. The second patient (aged 52, also Caucasian) developed stage 4 chronic kidney disease and nephrotic proteinuria (protein/ creatinine ratio $1821 \mathrm{~g} / \mathrm{mol}$ ) after accidental rupture of the inferior vena cava during a gastric bypass operation. On split-urine collection, both had a much higher degree of proteinuria during the day than during the night, compatible with orthostatic proteinuria. At further work-up, inferior vena cava thrombosis was diagnosed in both patients, whereas renal veins were patent.
\end{abstract}

Discussion: After simple anticoagulation in the first case, and anticoagulation plus endovascular recanalization in the second, there was almost complete resolution of the orthostatic proteinuria and a strong improvement of the estimated glomerular filtration rate in both patients. These cases highlight that nephrotic-range proteinuria can be linked to inferior vena cava thrombosis, and that a split-urine collection may also be very useful in the diagnostic work-up of proteinuria in adults.

Keywords: Nephrotic syndrome, Inferior vena cava, Orthostatic proteinuria

\section{Background}

Nephrotic-range proteinuria is a common reason for nephrological referral in clinical practice, and defined as renal protein loss of more than $3.5 \mathrm{~g} / 24$ hours. It can occur in the absence or presence or presence of edema and hypoalbuminemia $(<35 \mathrm{~g} / \mathrm{l})$. The latter situation is known as nephrotic syndrome [1].

\footnotetext{
*Correspondence: yana.apostolova@chuv.ch

${ }^{1}$ Department of Internal Medicine, University Hospital of Lausanne

and University of Lausanne (CHUV), Rue du Bugnon 46, 1011 Lausanne, Switzerland

Full list of author information is available at the end of the article
}

Nephrotic-range proteinuria with or without nephrotic syndrome can be caused by a wide variety of diseases. Frequent causes include different forms of glomerulonephritis (minimal change disease, membranous nephropathy, and focal segmental glomerulosclerosis). Among the secondary causes are systemic diseases such as diabetes mellitus, amyloidosis, lupus, and different types of vasculitis. The initial work-up of proteinuria includes extensive blood and urine testing, and is often followed by a kidney biopsy if the cause remains uncertain. Urine tests include dipstick analysis, microscopic analysis of the urinary sediment, and quantification of the degree of proteinuria. For quantification, random urine samples original author(s) and the source, provide a link to the Creative Commons licence, and indicate if changes were made. The images or other third party material in this article are included in the article's Creative Commons licence, unless indicated otherwise in a credit line to the material. If material is not included in the article's Creative Commons licence and your intended use is not permitted by statutory regulation or exceeds the permitted use, you will need to obtain permission directly from the copyright holder. To view a copy of this licence, visit http://creativecommons.org/licenses/by/4.0/. The Creative Commons Public Domain Dedication waiver (http://creativeco mmons.org/publicdomain/zero/1.0/) applies to the data made available in this article, unless otherwise stated in a credit line to the data. 
or 24 hour urine collections are used. In random urine samples, the ratio of total protein-to-creatinine ratio (expressed as g protein/mol creatinine) is measured as a proxy of 24 hours proteinuria. Split day and night urine collections are only rarely performed, except in children where they can point towards underlying orthostatic proteinuria.

Orthostatic proteinuria is defined as an abnormally large amount of protein excreted in urine when the patient is in an upright position, versus a normal or absent amount in the supine position. This condition is usually benign and of uncertain etiology, although it is sometimes linked to a compromised return of blood in the left renal vein caused by compression by the superior mesenteric artery (so called nutcracker phenomenon) [2] . Orthostatic proteinuria affects mostly children and adolescents, and often resolves without any treatment [3].

The following two cases demonstrate that spliturine collection might also be useful in the work-up of nephrotic-range proteinuria in adults and point towards an unusual cause of proteinuria.

\section{Case presentation \\ Case 1}

A 46 year old female Caucasian patient consulted the emergency department for right-sided flank pain. The patient had history of type 2 diabetes mellitus, obstructive sleep apnea syndrome, and schizoaffective disorder. She was treated with oral antidiabetic drugs (metformin and sitagliptin) and antipsychotics (valproate and amisulpride). She also suffered from morbid obesity and weighed $207 \mathrm{~kg}$, with a height of $1.64 \mathrm{~m}$ (body mass index of $77 \mathrm{~kg} / \mathrm{m}^{2}$ ).

The clinical examination revealed distension of superficial veins of the abdominal wall (see Fig. 1) and tenderness over the right abdominal flank. She also had chronic lymphedema of the legs.

The laboratory values on admission showed an increased level of creatinine $(115 \mu \mathrm{mol} / \mathrm{l}$, normal range: 44-80 $\mu \mathrm{mol} / \mathrm{l})$, compared with a baseline value of $80 \mu \mathrm{mol} / \mathrm{l}$. The rest of the laboratory values were normal [albumin $39 \mathrm{~g} / \mathrm{l}(N=35-52 \mathrm{~g} / \mathrm{l})$ ], liver function tests were all within normal range, leukocytes $7.0 \mathrm{Giga} / \mathrm{l}(N=$ 4.0-10.0 G/l), hemoglobin $141 \mathrm{~g} / \mathrm{l}(N=117-157 \mathrm{~g} / \mathrm{l})$, and thrombocytes $168 \mathrm{G} / \mathrm{l}(N=150-350 \mathrm{G} / \mathrm{l}))$, except $\mathrm{C}$-reactive protein level that was slightly elevated at $30 \mathrm{mg} / \mathrm{l}$ $(N<10 \mathrm{mg} / \mathrm{l})$.

Urine dipstick analysis did not show leukocytes or erythrocytes, but the presence of protein. A random urine spot sample confirmed the presence of proteinuria, with a urine protein-to-creatinine ratio (uPCR) of $4485 \mathrm{~g} /$ $\mathrm{mol}(N<10)$, corresponding to an estimated daily protein excretion rate of $44 \mathrm{~g} /$ day; of note, $1 \mathrm{~g} / \mathrm{mol}$ corresponds

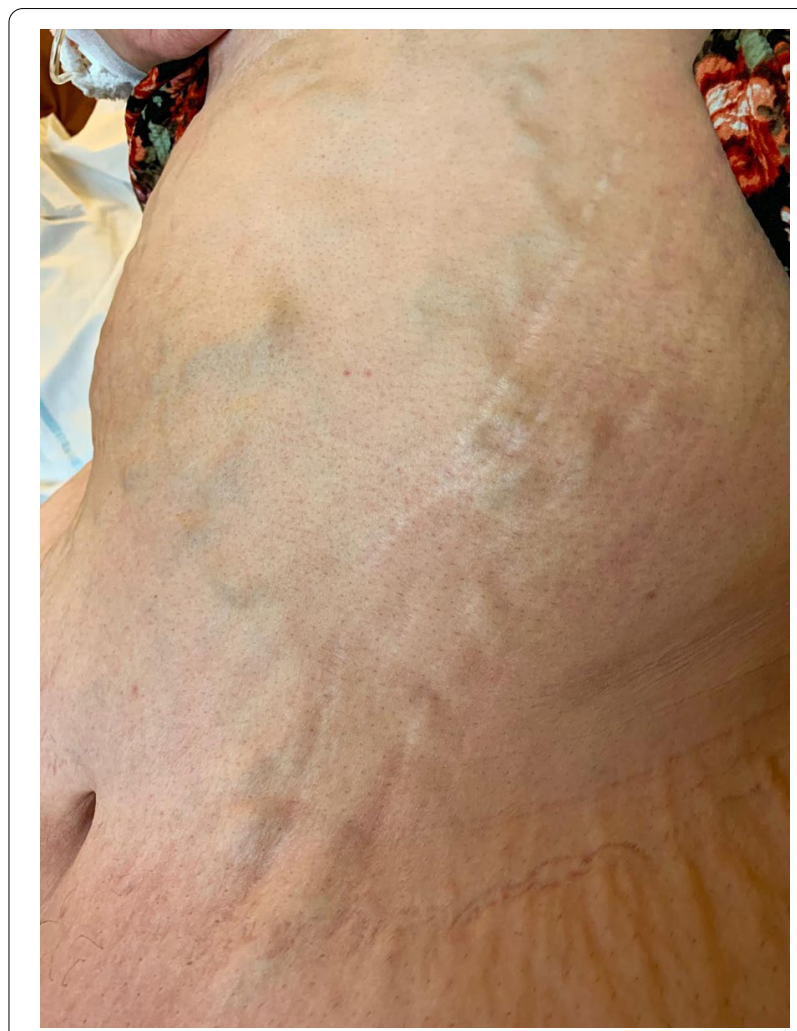

Fig. 1 Extreme obesity with overhanging abdomen and distended superficial abdominal veins at first presentation of patient 1

to $1 \mathrm{mg} / \mathrm{mmol}$ [4-6]. The urine protein electrophoresis showed albumin, but no paraproteins.

The patient refused hospitalization but accepted an outpatient nephrology consultation that took place 2 days later. The creatinine level had gone up 48 hours later, from 115 to $178 \mu \mathrm{mol} / \mathrm{l}$. To our surprise, a significant decrease of the proteinuria was noted, with a protein/ creatinine ratio of $194 \mathrm{~g} / \mathrm{mol}$. Of interest, the nephrology consultation took place in the morning, whereas the emergency visit took place during the evening, as seen in orthostatic proteinuria.

Although the initial diagnostic hypothesis for the rapid renal function loss included glomerulonephritis (FSGS, minimal change or membranous glomerulonephritis) or diabetic nephropathy, the collateral abdominal circulation and the orthostatic proteinuria raised the suspicion of an alternative cause, such as obstruction of the renal veins or inferior vena cava.

To rule out thrombosis and to assess the feasibility of kidney biopsy, a computed tomography $(\mathrm{CT})$ scan with iodine contrast was performed. The CT showed extensive thrombosis of the suprarenal inferior vena cava without thrombosis in the renal veins and portal vein (Fig. 2). This time, the patient accepted hospitalization and she 


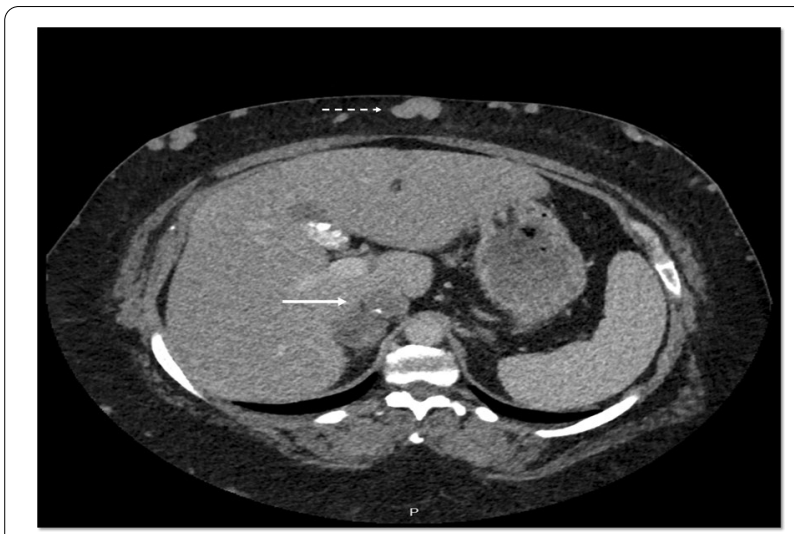

Fig. 2 Contrast-enhanced CT scan of patient 1: IVC thrombosis (bottom arrow) and collateral abdominal veins (top, notched arrow) are clearly visible

was admitted to the hospital for intravenous heparin. The immunological work-up [antinuclear factor (ANF), antineutrophil cytoplasmic (ANCA), antiglomerular basal membrane (anti-GBM), and antiphospholipase A2 (antiPLA2) antibodies] was negative. During hospitalization, split urine collection was performed and showed elevated uPCR values during the day $(595 \mathrm{~g} / \mathrm{mol})$ compared with the night (early morning sample: $45 \mathrm{~g} / \mathrm{mol}$ ), see Table 1 for details.

The renal function improved progressively, and distention of the superficial abdominal collateral veins diminished. A kidney biopsy was not performed for technical reasons. The patient was discharged on oral anticoagulation with anti-vitamin $\mathrm{K}$ (acenocoumarol). The follow-up $\mathrm{CT}$ at 3 months confirmed a partial recanalization of the inferior vena cava, and laboratory testing showed a further decrease in uPCR $(45 \mathrm{~g} / \mathrm{mol}$ in a random afternoon sample).

\section{Case 2}

This 52-year-old Caucasian female was referred to our nephrology clinic for investigation of nephrotic range proteinuria and a recent rise in creatinine levels. Her medical history included a left nephrectomy that had been performed 10 years earlier for pyonephrosis secondary to obstructive nephrolithiasis. Seventeen months prior to the current consultation, she had undergone a surgical intervention abroad; the goal was a gastric bypass, but the surgery was interrupted because of an early accidental rupture of the inferior vena cava and gall bladder. A cholecystectomy was performed, as well as primary repair of the blood vessel. A few days after the surgery, a control CT scan showed suprarenal inferior vena cava (IVC) thrombosis without renal vein thrombosis. Oral anticoagulation (apixaban) was initiated and continued for 6 months. Five months before the actual consultation, she underwent a control abdominal CT-scan. This scan showed persistent suprarenal IVC thrombosis that now expanded in the extra-hepatic veins; besides, a collateral circulation had developed via the azygos veins. Renal function worsened progressively, with a rise in creatinine from 126 to $248 \mu \mathrm{mol} / \mathrm{l}$, and spot urinary analysis showed nephrotic-range proteinuria, which motivated nephrological consultation.

Despite worsening renal function, the patient was asymptomatic. At clinical examination, her blood pressure was $117 / 83 \mathrm{mmHg}$ while taking three antihypertensive drugs [a calcium inhibitor (amlodipine), renin-angiotensin system (RAS) inhibitor (irbesartan), and a beta blocker (bisoprolol)]. Heart and lung auscultation were normal and she did not have malleolar edema. Her BMI was $39 \mathrm{~kg} / \mathrm{m}^{2}$ (weight $89 \mathrm{~kg}$, height $1.51 \mathrm{~m}$ ). There was no hematuria or leukocyturia in the urinary sediment. In a random urine sample, the uPCR was $1821 \mathrm{~g} / \mathrm{mol}$, corresponding to an estimated protein excretion of $18 \mathrm{~g} /$ day. Albumin accounted for $64 \%$ of the total proteinuria. Basic immunological work-up (antinuclear

Table 1 Summary of the laboratory results of patient one

\begin{tabular}{|c|c|c|c|c|c|}
\hline \multirow[t]{2}{*}{ Date } & \multicolumn{2}{|c|}{$\begin{array}{l}\text { Urine protein/creatinine }(\mathrm{g} / \mathrm{mol} \text {, } \\
N<10)\end{array}$} & \multicolumn{2}{|c|}{$\begin{array}{l}\text { Urine albumin/creatinine }(\mathrm{mg} / \\
\mathrm{mmol}, N<3)\end{array}$} & \multirow{2}{*}{$\begin{array}{l}\text { Creatinine } \\
(\mu \mathrm{mol} / \mathrm{l}, N= \\
44-80)\end{array}$} \\
\hline & Day & Night & Day & Night & \\
\hline Emergency presentation, day 1 & 4485 & & 2910 & & 134 \\
\hline Day 3, nephrology outpatient clinic & & 194 & & 119 & 178 \\
\hline Day 4, hospitalization & 1498 & & 935 & & 153 \\
\hline $\begin{array}{l}\text { Day 6, split urine collection; anticoagulation } \\
\text { started }\end{array}$ & $595^{\mathrm{a}}$ & 45 & $335^{\mathrm{a}}$ & 15.3 & \\
\hline Day 26, nephrology outpatient clinic & 194 & & 109 & & 82 \\
\hline
\end{tabular}

${ }^{a}$ Result of 24 hour urine collection 
factor, antiphospholipase A2 antibodies, antineutrophil cytoplasmic antibodies, anti-double-stranded-DNA antibodies, antiglomerular basal membrane antibodies, complement factor $\mathrm{C} 3$ and $\mathrm{C} 4$ ) and serologic tests for HIV and hepatitis $B$ and $C$ were all negative. Circulating albumin, C-reactive protein (CRP), electrolytes, and liver function tests were all within normal range, and there were no paraproteins. The initial working diagnosis was glomerulonephritis due to minimal change disease or membranous nephropathy. However, the risk of performing a kidney biopsy was considered too high in the setting of a single kidney, the venous collateral circulation, and the apixaban that could not be easily stopped.

As alternative diagnosis, and in analogy with the first case, we hypothesized that the extensive IVC thrombosis could be partly responsible. To further examine this possibility, we obtained a split urine sample. There was a significant difference in urine protein secretion between the morning (uPCR of $1.5 \mathrm{~g} / \mathrm{mol}$ ) and the afternoon sample (uPCR $1153 \mathrm{~g} / \mathrm{mol}$, Table 2). This result suggested that the renal venous congestion was more pronounced in the upright position.

Table 2 Summary of the laboratory results of patient two

\begin{tabular}{|c|c|c|c|c|c|}
\hline \multirow[t]{2}{*}{ Date } & \multicolumn{2}{|c|}{$\begin{array}{l}\text { Urine protein/creatinine ratio } \\
(\mathrm{g} / \mathrm{mol}, N<10)\end{array}$} & \multicolumn{2}{|c|}{$\begin{array}{l}\text { Urine albumin/creatinine ratio } \\
(\mathrm{mg} / \mathrm{mmol}, N<3)\end{array}$} & \multirow{2}{*}{$\begin{array}{l}\text { Creatinine } \\
\text { ( } \mu \mathrm{mol} / \mathrm{l}, \mathrm{N}= \\
44-80)\end{array}$} \\
\hline & Standing & Supine & Standing & Supine & \\
\hline First nephrological consultation, 1 year after operation & 1821 & & 1175 & & 164 \\
\hline Follow up consultation, split urine collection & 1153 & 15 & 767 & 4.2 & 133 \\
\hline One month after recanalization & $15^{\mathrm{a}}$ & $0.74^{\mathrm{a}}$ & $8^{\mathrm{a}}$ & $3^{a}$ & $53^{\mathrm{a}}$ \\
\hline
\end{tabular}

${ }^{a}$ Results of 24 hour urine collection
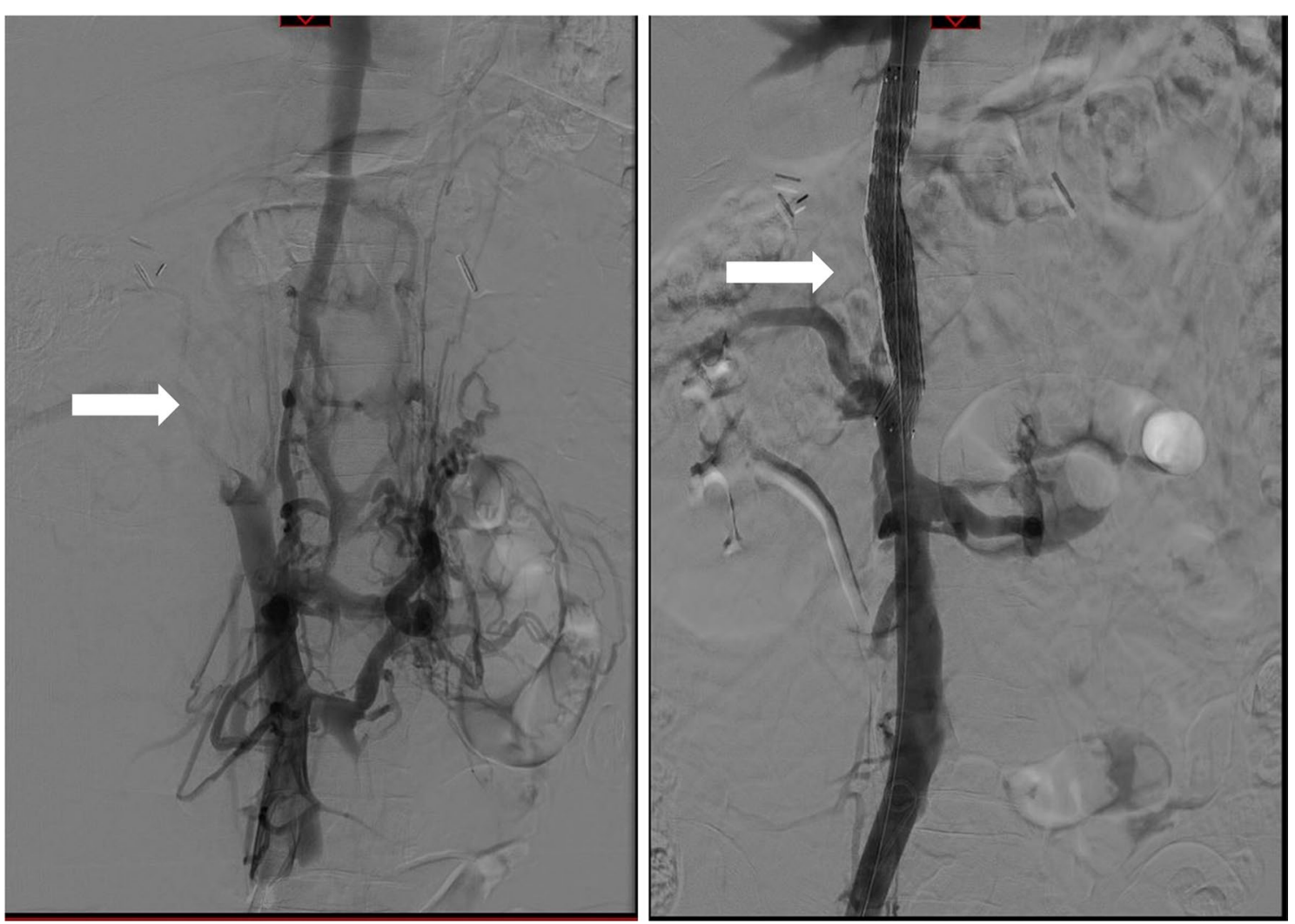

Fig. 3 Angiography before (left) and after (right) revascularisation of the IVC in patient 2. Localization of the IVC thrombosis is shown with an arrow (left figure), as is the stent (right figure). Note the disappearance of the collateral circulation around the IVC and the left kidney. Angiography before and end-vascular revascularisation procedure with recanalization and stunting if the IVC in patient two 
As a proof of principle, the patient underwent a successful endovascular revascularization procedure with recanalization and stenting of the IVC (Fig. 3). Hereafter, renal function recovered completely and the proteinuria disappeared, without any other change in therapy (Table 2).

\section{Discussion}

In this article, we describe the clinical presentation, diagnostic procedures, and treatment of two patients with IVC thrombosis. Both patients presented with nephroticrange proteinuria of orthostatic nature that diminished or even disappeared after systemic anticoagulation and/ or recanalization of the IVC, respectively, suggesting that IVC thrombosis was the most likely cause of their proteinuria.

Although renal vein thrombosis is a well-known complication of nephrotic syndrome in patients with glomerulonephritis, the opposite (thrombosis as a cause of proteinuria) has rarely been described. As for IVC thrombosis, to the best of our knowledge, only one article (published in 1962) has previously reported that isolated thrombosis of the IVC can cause nephrotic range proteinuria [7]. However, at the time CT scans were not available, and associated renal vein thrombosis was not excluded with certainty. Renal vein thrombosis in association with IVC thrombosis has been reported in several articles as a cause of nephrotic syndrome [8-12]. All reported cases improved after anticoagulation.

The diagnostic clue to the presence of a possible IVC thrombosis was the presence of orthostatic proteinuria in both patients.

Classically, orthostatic proteinuria points towards an underlying nutcracker syndrome, especially in adolescents, although it can also be encountered in adults [3]. The nutcracker syndrome is characterized by the entrapment of the left renal vein between the aorta and the superior mesenteric artery. It is hypothesized that this leads to venous hypertension and ruptures in the septa between the small veins and collecting systems of the renal fornix, thus explaining the hematuria. Besides, venous hypertension may lead to a release of norepinephrine and angiotensin II, especially in the upright position when the renal vein is further compressed. As a consequence, transglomerular pressure and glomerular permeability for proteins increase, explaining the orthostatic proteinuria $[13,14]$. The CT scans in our patients did not show any signs of underlying nutcracker syndrome. Moreover, this syndrome is often associated with lower BMI [2], whereas our patients were obese.

Nevertheless, a similar mechanism may explain the orthostatic proteinuria observed in our cases. IVC thrombosis may increase the pressure in the renal veins and also increases the transglomerular pressure, ultimately leading to proteinuria and reduced glomerular filtration rate. Obesity may reinforce this phenomenon. Indeed, the pressure gradient between the thoracic and abdominal vena cava and the intra-abdominal pressure are higher in obese patients than in controls, and increase further in the standing position [15]. This phenomenon may explain the fluctuations in proteinuria observed in our patients, despite the fixed IVC thrombosis.

Although this is an attractive hypothesis, we have no proof that these mechanisms were indeed present in the present cases, as renal venous pressures were not measured.

After IVC thrombosis, collateral circulations will ultimately develop, especially via the azygos system. This could diminish (but possibly not normalize) the pressure in the renal veins [16]. The collateral, abdominal venous circulation offered an important clue to the underlying diagnosis of IVC thrombosis in the first patient. Of interest, the collateral circulation quickly disappeared after recanalization of her IVC.

A major limitation in our case reports is the lack of renal biopsies, and we can therefore not exclude the possibility that underlying glomerulonephritis was present in one or both patients. For technical reasons (extreme obesity in patient one and a single kidney in patient two on anticoagulation), renal biopsies were not performed. However, immunological work-up was negative in both cases, and urinary sediments were inactive. Besides, the abrupt reductions in proteinuria after anticoagulation (heparin followed by acenocoumarol) in the first case and endovascular recanalization in the second are strong arguments for a causal link between IVC thrombosis and the nephrotic range proteinuria. Neither of our patients received immunosuppressive treatment, but still had normal renal function during the follow-up, 2 years after the first event.

The cause of IVC thrombosis in the second case was straightforward, as it was a direct complication of a surgical intervention. In the first case, its etiology is less certain. IVC thrombosis is an underdiagnosed pathology with high morbidity and mortality. The IVC thrombosis is often associated with malignancies owing to their prothrombotic properties or direct invasion of the vessel wall (typically renal cell carcinoma). Thrombophiliarelated conditions such as antiphospholipid antibody syndrome, hormone replacement therapy, pregnancy, and chronic inflammatory conditions have also been associated with IVC thrombosis. An overview of the possible causes of IVC thrombosis is presented in Table 3 [17]. None of these factors were present in the first patient. The most striking feature of the first patient was her extreme obesity (BMI $77 \mathrm{~kg} / \mathrm{m}^{2}$ ). Although obesity is 
Table 3 Frequent causes of IVC thrombosis according to the underlying mechanism

\begin{tabular}{|c|c|c|}
\hline Endothelial damage & Stasis & Coagulopathy \\
\hline $\begin{array}{l}\text { Endovascular intervention } \\
\text { Surgery } \\
\text { Abdominal trauma }\end{array}$ & $\begin{array}{l}\text { Dehydration } \\
\text { Hypovolemia } \\
\text { Obesity } \\
\text { Congenital IVC anomalies } \\
\text { External compression }\end{array}$ & $\begin{array}{l}\text { Nephrotic syndrome } \\
\text { Thrombophilia } \\
\text { Factor V Leiden } \\
\text { Antiphospholipid syndrome } \\
\text { Jak } 2 \\
\text { Syndrome protein S/C }\end{array}$ \\
\hline
\end{tabular}

not recognized as an isolated cause of IVC thrombosis, we believe that the extreme obesity played a major role in the first patient. First of all, she was largely immobilized as she could hardly move because of her obesity. Secondly, obesity is associated with increased intra-abdominal pressure and reduced venous blood flow velocity, which further increased her thrombotic risk [18].

Anticoagulation, either by heparin, vitamin K antagonists, direct Xa inhibitors, or a combination of these molecules, is the mainstay of treatment for patients with IVC thrombosis. To the best of our knowledge, there are no comparative studies among these different molecules, and the choice should therefore, in our opinion, be based on local expertise. Adjunctive therapeutic modalities may be useful in selected patients, depending on the acuity of their presentation. For example, in patients with acute (< 14 days) or sub-acute (15-28 days) presentation who are not at high risk for bleeding, catheter-directed thrombolysis has been successfully applied [19]. Whereas those with chronic presentation ( $>28$ days) may benefit from percutaneous transluminal angioplasty (PTA), and stenting alone remains uncertain. To the best of our knowledge, only one study assessed the efficacy and longterm prognosis of endovascular management [20]. In this Indian study of 12 cases of chronic IVC thrombosis, all the cases had an immediate and long-term (follow-up of 13 years) procedural success (recanalization $+/$ - stenting), without any complications. Only one case had restenosis, which was successfully managed by stenting. No data were provided on proteinuria in this study.

\section{Conclusion}

The association of isolated IVC thrombosis and proteinuria has been rarely reported in medical literature, but should be considered in patients with orthostatic proteinuria, the presence of a collateral abdominal venous circulation, and a negative immunological work-up for glomerulonephritis. The presented cases suggest that morbid obesity may be a risk factor for this clinical entity, although more studies are necessary to support this hypothesis. A computerized tomography scan with intravenous contrast is the preferred radiological exam to confirm the diagnosis, as Doppler echography may be inconclusive, especially in obese individuals. Patients should be treated with anticoagulation. Whether or not endovascular treatment is indicated should be decided on an individual basis. Endovascular treatment can lead to spectacular improvement in renal function and proteinuria, as shown in this case report.

\section{Abbreviations}

IVC: Inferior vena cava; BMI: Body mass index; NRP: Nephrotic range proteinuria; FSGS: Focal segmental glomerulosclerosis.

\section{Acknowledgements}

The authors wish to thank Mrs. Wendy Brito for her help in the selection of the radiological images and Dr. Sophie Martin Du Pan for her correction of English grammar and writing.

\section{Authors' contributions}

PM: drafted, reviewed, and conceptualized the manuscript. YA: drafted, reviewed, conceptualized, and edited the manuscript. SQ: reviewed and conceptualized the manuscript. MP: conceptualized, reviewed, edited, and oversaw the manuscript. All authors read and approved the final manuscript.

\section{Funding}

None.

\section{Availability of data and materials}

Data sharing is not applicable to this article as no datasets were generated or analyzed during the current study.

\section{Declarations}

Ethics approval and consent to participate

Both patients gave oral and written permission to publish their cases.

\section{Consent for publication}

Written informed consent was obtained from the patient for publication of this case report and any accompanying images. A copy of the written consent is available for review by the Editor-in-Chief of this journal.

\section{Competing interests}

Authors declare no conflicts of interest

\section{Author details}

${ }^{1}$ Department of Internal Medicine, University Hospital of Lausanne and University of Lausanne (CHUV), Rue du Bugnon 46, 1011 Lausanne, Switzerland. ${ }^{2}$ Service of Nephrology, Riviera-Chablais Hospital, Rennaz, Switzerland. ${ }^{3}$ Department of Radiology, Interventional Radiology, University Hospital of Lausanne and University of Lausanne, Lausanne, Switzerland. ${ }^{4}$ Service of Nephrology, University Hospital of Lausanne and University of Lausanne, Lausanne, Switzerland.

Received: 12 September 2020 Accepted: 24 September 2021

Published online: 25 November 2021 


\section{References}

1. McCloskey O, Maxwell AP. Diagnosis and management of nephrotic syndrome. Practitioner. 2017;261(1801):11-5.

2. Kurklinsky AK, Rooke TW. Nutcracker phenomenon and nutcracker syndrome. Mayo Clin Proc. 2010;85(6):552-9.

3. Uehara K, Tominaga N, Shibagaki Y. Adult orthostatic proteinuria. Clin Kidney J. 2014;7(3):327-8.

4. Fotheringham J, Campbell MJ, Fogarty DG, El Nahas M, Ellam T. Estimated albumin excretion rate versus urine albumin-creatinine ratio for the estimation of measured albumin excretion rate: derivation and validation of an estimated albumin excretion rate equation. Am J Kidney Dis. 2014:63(3):405-14.

5. Lemann J Jr, Doumas BT. Proteinuria in health and disease assessed by measuring the urinary protein/creatinine ratio. Clin Chem. 1987;33(2 Pt 1):297-9.

6. Ralston SH, Caine N, Richards I, O'Reilly D, Sturrock RD, Capell HA. Screening for proteinuria in a rheumatology clinic: comparison of dipstick testing, 24 hour urine quantitative protein, and protein/creatinine ratio in random urine samples. Ann Rheum Dis. 1988;47(9):759-63.

7. Baird WL Jr, Buchanan DP. The nephrotic syndrome following thrombosis of the inferior vena cava. Am J Med. 1962;32:128-30.

8. Araujo MP, Goncalves C, Goncalves R, Braga Junior JW, Peterson TV, Atallah AN, Sato El, Trevisani VF. Vena cava thrombosis associated with nephrotic syndrome in the puerperal gestational cycle. Sao Paulo Med J. 2001;119(1):24-8.

9. Janvier AL, Hamdan H, Malas M. Bilateral renal vein thrombosis and subsequent acute renal failure due to IVC filter migration and thrombosis. Clin Nephrol. 2010;73(5):408-12.

10. Morrissey EC, McDonald BR, Rabetoy GM. Resolution of proteinuria secondary to bilateral renal vein thrombosis after treatment with systemic thrombolytic therapy. Am J Kidney Dis. 1997:29(4):615-9.

11. Sandhu G, Bansal A, Ranade A, Jones J, Cortell S. Bilateral renal vein thrombosis can cause nephrotic range proteinuria. QJM 2014;107(9):763-5.
12. Blagova OV, Dzemeshkevich SL, Kozlovskaia NL, Nedostup AV, Sarkisova ND, Frolova luV, Raskin W, Dzemeshkevich AS, Abugov SA, Skipenko $\mathrm{OG}$, et al. Successful treatment of massive thrombosis of the vena cava inferior with nephrotic syndrome and chronic bilateral pulmonary artery thromboembolism in a patient with genetic thrombophilia. Ter Arkh. 2012;84(1):41-7.

13. Barbey F, Venetz JP, Calderari B, Nguyen QV, Meuwly JY. Orthostatic proteinuria and compression of the left renal vein (nutcracker syndrome). Presse Med. 2003:32(19):883-5.

14. Vehaskari VM. Mechanism of orthostatic proteinuria. Pediatr Nephrol. 1990:4(4):328-30.

15. Linicus Y, Kindermann I, Cremers B, Maack C, Schirmer S, Bohm M. Vena cava compression syndrome in patients with obesity presenting with edema and thrombosis. Obesity (Silver Spring). 2016;24(8):1648-52.

16. Kapur S, Paik E, Rezaei A, Vu DN. Where there is blood, there is a way: unusual collateral vessels in superior and inferior vena cava obstruction. Radiographics. 2010;30(1):67-78.

17. McAree BJ, O'Donnell ME, Fitzmaurice GJ, Reid JA, Spence RA, Lee B. Inferior vena cava thrombosis: a review of current practice. Vasc Med. 2013;18(1):32-43.

18. Klovaite J, Benn M, Nordestgaard BG. Obesity as a causal risk factor for deep venous thrombosis: a Mendelian randomization study. J Intern Med. 2015;277(5):573-84.

19. Alkhouli M, Morad M, Narins CR, Raza F, Bashir R. Inferior vena cava thrombosis. JACC Cardiovasc Interv. 2016;9(7):629-43.

20. Srinivas BC, Dattatreya PV, Srinivasa KH, Prabhavathi, Manjunath CN. Inferior vena cava obstruction: long-term results of endovascular management. Indian Heart J. 2012;64(2):162-9.

\section{Publisher's Note}

Springer Nature remains neutral with regard to jurisdictional claims in published maps and institutional affiliations.
Ready to submit your research? Choose BMC and benefit from:

- fast, convenient online submission

- thorough peer review by experienced researchers in your field

- rapid publication on acceptance

- support for research data, including large and complex data types

- gold Open Access which fosters wider collaboration and increased citations

- maximum visibility for your research: over $100 \mathrm{M}$ website views per year

At BMC, research is always in progress.

Learn more biomedcentral.com/submissions 